\title{
Are two brands better than one? Investigating the effects of co-branding in advertising on audience memory
}

\author{
${\text { Cathy } \text { Nguyen }^{1} \text { (D) Jenni Romaniuk }}^{1}$. \\ Margaret Faulkner $^{1} \cdot$ Justin Cohen ${ }^{1}$
}

Published online: 13 November 2017

(C) Springer Science+Business Media, LLC 2017

\begin{abstract}
Co-branded advertising, where advertisements feature two partnered brands from different categories, should ideally benefit both brands. We test this assertion by studying the effect of featuring a second brand in advertisements on ad and brand name memorability, and the role of category context on which brand is recalled. Our test covers online display advertisements for consumer-packaged brands paired with charity and retailer brands in three markets (USA, UK, and Australia). Independent sample comparisons across 54 brand pairs show that advertising two brands has a neutral effect on ad memorability and negative effect on brand memorability. Furthermore, the advertisement's category context determines which of the brands is recalled. Our findings support a competitive interference theory of dual-brand processing, whereby the two brands compete for attention resources. The results have implications for the return on investment from advertising expenditure, which will vary substantively depending on whether the costs of advertising are shared or borne by one brand in the pair.
\end{abstract}

Keywords Co-branding $\cdot$ Advertising and brand recall $\cdot$ Competitive interference

Cathy Nguyen

Cathy.Nguyen@MarketingScience.info

Jenni Romaniuk

Jenni.Romaniuk@MarketingScience.info

Margaret Faulkner

Margaret.Faulkner@MarketingScience.info

Justin Cohen

Justin.Cohen@MarketingScience.info

1 Ehrenberg-Bass Institute-University of South Australia, 70 North Terrace, Adelaide,

SA 5000, Australia 


\section{Introduction}

Co-branding involves deliberately pairing two brands in any collaborative marketing effort (Grossman 1997). The lure of a co-branded advertising strategy can be linked to signaling theories, whereby a brand can quickly borrow the mental associations of another brand by appearing in the same context (Rao et al. 1999). Such theories are supported by findings that co-branding helps unknown or less familiar brands to build brand associations and improve perceived quality and attitudes (Voss and Gammoh 2004). Consequently, marketing strategies that feature more than one brand continue to grow (Bloom et al. 2006; Lee Thomas et al. 2011).

While it is accepted that advertising only "works" when an audience remembers the advertisement and brand (Romaniuk 2009; Rossiter and Bellman 2005), it is unclear whether co-branding in advertising facilitates or inhibits brand memory encoding or retrieval. It has been suggested that when two brands pool together their resources, they increase attention to advertising (Erdogan and Drollinger 2008). Here, the second brand acts as a familiar stimulus that activates deeper levels of processing among its brand users, who are more likely to notice the advertisement (Harrison 2013; Vaughan et al. 2016).

However, there is speculation that co-branding in advertising may actually hurt one or both brands promoted (Dahlén and Lange 2005; Romaniuk 2013). While not empirically tested, the presence of a second brand in advertising could trigger an interference effect, irrespective of the relationship between the brands, inhibiting audience recall of one or both brands (Bjork and Bjork 1996). Erfgen et al. (2015) express concerns that advertising with a secondary brand might disadvantage a company if it translates into poorer brand recall. Also highlighted by Wang and Muehling (2010, p.309), "One might question whether the potential positive benefits expected from co-branded advertising are outweighed by the potential negative consequences of 'sharing the limelight' with another brand."

This research seeks to shed light on whether existing concerns are warranted or whether co-branded advertising can achieve memory objectives beyond that achieved when advertising one brand. Using the online context, we investigate if a consumerpackaged goods (CPG) brand benefits from advertising with a charity or a retailer and how this pairing affects ad recognition, brand recall, and the influence of ad context on audience memory. Our study addresses numerous calls for research into co-branding effectiveness from advertising and cognitive-processing perspectives (Besharat and Langan 2014; Helmig et al. 2008; Leuthesser et al. 2003).

\section{Background}

To be effective, advertising must, at minimum, overcome two basic hurdles - attract attention and communicate the brand such that it is remembered (du Plessis 1994b; Kapferer 1995). However, it has always been difficult for advertisers to command the attention of their audience even in single-brand contexts, and especially within the online environment. Findings reveal that half of online banner advertisements receive virtually no visual attention at all (Dréze and Hussherr 2003) and only $14 \%$ of online ads are recalled by consumers (Peled 2010). Featuring multiple brands adds a layer of 
complexity to any advertisement and can further affect advertising and brand memories. In the following sections, we discuss the theoretical rational for our hypothesized effects of co-branding on ad and brand memorability.

\subsection{Impact of co-branded advertising on advertisement memorability}

A common assertion is that the presence of two brands increases attention to advertising (Atkin and Block 1983; Erdogan and Drollinger 2008), as this co-branding increases the overall level of familiarity of the advertisement, in line with the "Attention to the Familiar" phenomenon (Ahluwalia 2002; Kent and Allen 1994). Pechmann and Stewart (1990) posit that familiarity increases relevance; familiar stimuli have a lower perceptual threshold and are therefore easier to notice and process. Advertising familiarity is further enhanced by past brand usage, underpinned by a well-established empirical pattern showing that brand users are more likely to remember advertising than non-users (Harrison 2013; Vaughan et al. 2016). This usage-bias effect extends to celebrities who attract the attention of their fan base (Atkin and Block 1983). As co-branded advertising draws from the consumer bases of two brands rather than one, it should naturally reach a higher proportion of "users" than either brands advertising alone. Consistent with this "extended usage-bias" effect, cobranded advertising attracts the second brand's user base, who are disproportionately more drawn to the advertisement. Therefore, we propose the following:

H1: Ad memorability is higher when two brands are present in advertising than when one brand is present.

\subsection{Impact of co-branded advertising on memory of the brand}

While the presence of a second brand in advertising may produce a positive effect for ad memorability, we anticipate that it interferes with retrieval and impairs the ability to remember an item when it is linked to similar items in memory (Bettman 1979; Blankenship and Whitely 1941). Anderson and Neely (1996) suggest that interference arises when a retrieval cue normally used to access a piece of information becomes associated with additional items. When a cue is linked to more than one item in memory, all items compete with the target (e.g., brand name) for access to conscious awareness (Bjork and Bjork 1996). Interference effects inhibit the retrieval of advertising information such as in Burke and Srull's (1988) study, where respondents had difficulty retrieving advertising information when they were also exposed to adverts for competitor brands. Studies also show that the more advertisements people are exposed to within a given period, the less information they are able to remember from any one ad (Danaher et al. 2008).

While interference effects are typically linked to brands in the same product class, Levin and Levin (2000) speculate that co-branded advertising can also evoke comparisons between brands in different categories. This suggests that co-advertised brands compete against each other for attention and retrieval. A quote by Venkatesh et al. (2000, p.4) depicts this catch-22, "In essence, co-marketing alliances are breeding grounds for endogenous competition, even when such competition is unintended." Preliminary evidence for this is found in Schmidt and Hitchon's (1999) research, where 
the inclusion of a social issue within a print advertisement (for denture cream) inhibited other information about the brand being remembered. Therefore, we hypothesize a "dual-brand memory interference" effect, such that:

$H 2$ : Brand memorability is lower when two brands are present in advertising than when one brand is present.

\subsection{Ad-context congruency of co-branded advertising}

Ideally, audiences of co-branded advertising are left with an impression of both brands. However, when two brands are featured in one advert, one brand is usually the primary focus while the other brand receives less attention (Wang and Muehling 2010). Our final hypothesis focuses on ad-context congruency that is the extent to which there is a match between the brand and context in which it is placed (Dahlén and Lange 2005). When the creative elements of an advertisement (e.g., visuals, slogans) are directly related to a brand's product category, ad context is considered congruent with the brand. While prior research has focused on the congruency between brands in an advertising alliance (Washburn et al. 2000), there are no known studies on the congruency of the ad context and individual brands in co-branded advertisements. When two featured brands are from the same category, ad context will have an equally distributed influence; however, when two brands are from different categories, the advertising context may play a role in the memory for brands.

Prior studies show that the congruency of elements in advertising leads to more efficient processing and retrieval of advertising information. One example, Yi (1990), shows that priming a certain attribute within an advertisement increases the probability that the attribute is used to process the ad information. By emphasizing a given product category in co-branded advertising, this should strengthen the category brand link in consumers' minds and, therefore, heighten awareness of the brand when that product category is cued (Gammoh et al. 2006). This is consistent with Wyer and Srull's (1981) "storage bin model," whereby a recently activated concept is placed on the top of a layered bin, and when processing new information, the construct at the top is accessed first. An "ad-context congruency" effect in co-branded advertising will mean that brand recall is higher when a brand owns the ad context and lower when a brand does not own the ad context (i.e., when it is the secondary brand advertised). Our final hypothesis is as follows:

H3: Ad-context congruency in co-branded advertising has a positive effect on brand recall for the congruent brand and a negative effect on the non-congruent brand.

\section{Research method}

\subsection{Brand pair types}

We explore the effect of co-branded advertising on two brand pair types: CPGs paired with charity brands and CPGs with retailer brands. Cause-related marketing (CPG- 
charity) and co-op advertising (CPG-retailer) both fit the conceptualization of cobranded advertising adopted in this study (Grossman 1997). Charities and retailers both feature alongside CPG brands in advertising and such arrangements are likely based on a cooperative alliance whereby both parties aim for a mutually beneficial "win-win" outcome (Helmig et al. 2008). These similarities suggest that consumers process charity and retailer brands similarly when they co-occur with CPG brands in advertising.

\subsection{Experimental procedure and sampling}

This study utilizes a between-subjects experiment to test the effects of a second brand in online display advertising. The experiment was administered in three countries: USA $(n=3015)$, UK $(n=3465)$, and Australia $(n=3805)$ between December 2014 and August 2016. Consumer respondents were recruited via email through panel management companies, where individuals opt in to complete surveys and are rewarded for their time. The sampling criteria included respondents between 18 and 65 years. A quota sampling approach was used to ensure that samples were broadly representative of the general population in each market in terms of age, gender, and city of residence.

To mask the purpose of the experiment and provide a realistic task and context, respondents were told that the study was about the types of articles that people typically read online. They were asked to read a series short articles which were sourced from popular online news sites (e.g., New York Times, Huffington Post). Respondents were told that the articles represent a format that mimics how they would appear in a real online setting, with no mention of advertising being made at any stage in the preamble. During the reading task, respondents were exposed to a series of static banner advertisements featured on the top of each article.

A dummy advertisement was placed at the start and end of the articles, with six test treatment ads in the middle of the reading task. In our split sample design, an individual either saw an advertisement for a CPG brand in the single-brand treatment or in a cobrand treatment featuring a charity or a retailer. Respondents were exposed to an equal number of single and co-branded advertisements. Each article was shown for a fixed $40 \mathrm{~s}$ which, according to a pre-test, was a sufficient time to read each article's content. Immediately after viewing the eight articles, all respondents completed the same distraction task. The task consisted of eight questions about the editorial content of the articles, consistent with how the research was positioned, followed by the keydependent measures.

Ad recognition Respondents were shown images of each banner advertisement with all brand references removed (in line with du Plessis 1994a). In a single-response question, we asked "Do you remember seeing the following ad whilst reading the articles earlier?" and respondents either indicated that they had seen the ad or not.

Singh et al. (1988) recommend the use of multiple dummies in any recognition task to limit respondent guessing, which could inflate recognition scores. When capturing ad recognition, respondents saw an equal number of dummy advertisements not present in the study stimuli, compared to actual advertisements. These dummy advertisements received recognition scores ranging from 6 to $10 \%$ across the three markets, reassuring us that guessing is not a cause for concern (in line with Dréze and Hussherr 2003). 
Brand recall Respondents who recognized an advertisement were later asked to identify the brand/s advertised in an open-text question. To avoid priming towards only single-brand mentions, respondents were asked, "Which brand/s were shown in this advertisement? You may list more than one brand if applicable." Similar methods of collecting brand recall data have been used in previous co-branded advertising studies (Dahlén and Lange 2005; Erfgen et al. 2015).

\subsection{Stimuli design and manipulation of treatments}

Our study included 54 brand pairs made up of 33 individual brands (18 CPG brands, six charity brands, and nine retailer brands). Each charity and retailer brand was paired with two CPG brands from a range of product categories (as depicted in Table 1). Prior to conducting this study, an expert panel pre-test was conducted to inform the creative for each ad (i.e., slogan and visuals) and to ensure that there is not a poor fit between brand pairs that might unduly attract participant attention or affect recall (Bigné et al. 2012).

The main manipulation of this study was the presentation of one or two brands in a banner advertisement. In the co-branded conditions, two brands are featured on either end of the banner. In single-brand conditions, one brand is featured on the left or right of the banner. Our exploration of online display advertisements showed that even in

Table 1 Summary of brands/brand pairs tested

\begin{tabular}{|c|c|c|c|}
\hline & $\begin{array}{l}\text { Charities } \\
\text { (paired with CPG brand) }\end{array}$ & $\begin{array}{l}\text { CPG brands } \\
\text { (paired with charity/retailer) }\end{array}$ & $\begin{array}{l}\text { Retailers } \\
\text { (paired with CPG brand) }\end{array}$ \\
\hline \multirow[t]{6}{*}{ USA } & & Colgate & Walmart \\
\hline & & Special K & Walmart \\
\hline & & Kleenex & Walgreens \\
\hline & & Pantene & Walgreens \\
\hline & & Yoplait & Kroger \\
\hline & & M\&Ms & Kroger \\
\hline \multirow[t]{6}{*}{ UK } & Cancer Research & Aquafresh & Tesco \\
\hline & Cancer Research & Velvet & Tesco \\
\hline & RSPCA & Müller & Sainsbury's \\
\hline & RSPCA & Galaxy & Sainsbury's \\
\hline & Red Cross & Weetabix & ASDA \\
\hline & Red Cross & TRESemmé & ASDA \\
\hline \multirow[t]{6}{*}{ Australia } & Cancer Council & Colgate & Coles \\
\hline & Cancer Council & Kelloggs & Coles \\
\hline & RSPCA & Kleenex & Woolworths \\
\hline & RSPCA & $\mathrm{M} \& \mathrm{Ms}$ & Woolworths \\
\hline & Salvation Army & Yoplait & IGA \\
\hline & Salvation Army & Pantene & IGA \\
\hline
\end{tabular}

NB: the US study tested the effects of CPG and retailer brand pairs only 
single-brand contexts, brands are usually shown on one side or the other, rather than in the middle of the banner. Brand visuals in both conditions were rotated from left to right to control for potential positioning effects. All other factors relating to the design of the ad and the articles were kept constant between treatments.

The verbatim responses from the unaided brand recall question confirm that respondents recognized that co-branded advertisements featured two brands, even if they did not remember the name of brands shown. Examples of brand recall responses where respondents were exposed to co-branded advertising include: "red cross and something else," "can't remember and RSPCA," "ASDA and something in red," "Aquafresh and something about cancer," and "Galaxy and a supermarket." These responses provide support for the success of the co-brand manipulation.

For each co-brand pair, two types of creative stimuli were designed: one where the background visual and slogan are in the context of the CPG brand and another where the creative stimulus is in the context of the charity or retailer (but non-congruent with the CPG brand) (Fig. 1). The ad context manipulation, which involved altering the background visual, slogan, and accompanying images, was done for the co-brand conditions only, as rarely will an advertisement for a single brand show a brand in a non-congruent context.

\section{Results}

To test H1, we ran a logistic regression using the co-brand treatment (versus the singlebrand treatment) as the independent variable, and ad-recognition and brand pair type as the dependent variables, with country included as a possible covariate. Our aim was to determine which of the dependent variables has the strongest relationship with estimating the presence of the co-brand treatment. The results show no statistically significant relationships (at $p<0.05$ level) with ad-recognition. This non-result is substantial for two reasons. First, it reflects the substance of the results, where out of 30 tests, only four co-branded treatments score higher than the single-brand treatment, while in 23 tests, ad recall is lower for the co-brand treatment (for three instances, the single- and co-brand treatment scores were identical). Second, based on the sample sizes, the low confidence intervals around the results meant that we would have

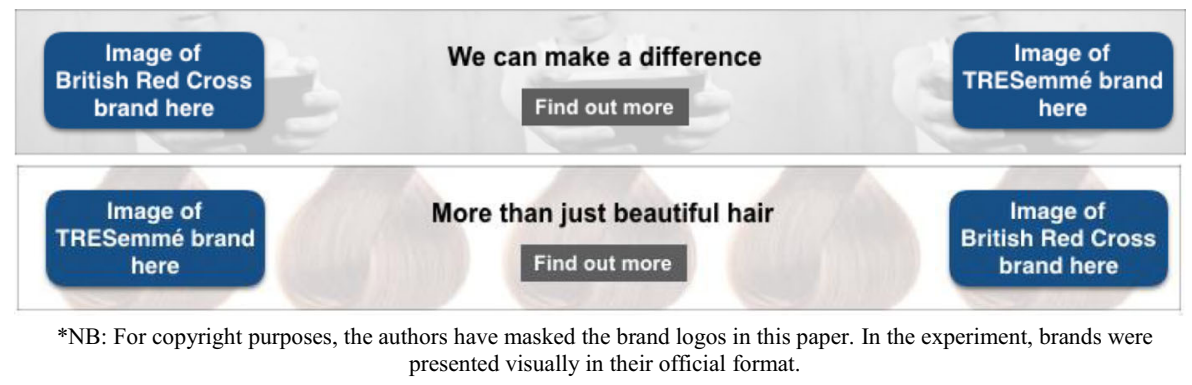

Fig. 1 Example of stimuli where a TRESemmé owns an ad context (Red Cross as secondary brand) and b Red Cross owns an ad context (TRESemmé as secondary brand). NB: For copyright purposes, the authors have masked the brand logos in this paper. In the experiment, brands were presented visually in their official format 
detected statistically significant results if differences had been as little as $\pm 15 \%$. Therefore, it is not simply a lack of statistical power that led to the non-statistically significant results. When we examine the results at the pair-type level, we find that being a charity in a co-brand arrangement is marginally significant at explaining the single/co-brand treatment $(p=0.06)$, but the direction is negative $(\beta=-0.02)$ such that co-branding is weakly associated with negative ad recognition. This suggests that there is no evidence that adding a second brand increases ad recognition; therefore, $\mathrm{H} 1$ is rejected.

To address $\mathrm{H} 2$ and $\mathrm{H} 3$, we ran a multinomial regression. The dependent variable was a three-category variable of the treatment conditions $(1=$ single brand, $2=$ cobrand non-congruent, and 3 = co-brand congruent). The control variable is the singlebrand treatment. As the analysis is to determine if the brand recall scores are higher for co-brand conditions than single conditions, and if there are different effects based on the context, the independent variables are brand recall and brand type (CPG or not). The country of the study was added as a dummy variable to detect any influence.

The results revealed that brand recall is negatively related to all co-brand treatments relative to single-brand treatments, with all $\operatorname{Exp}(B)$ figures statistically significant at $p<0.05$ level and lower than one (see Table 2). Therefore, $\mathrm{H} 2$ is supported. In relation to covariates, there were no significant effects for country dummy variables. However, brand type has some influence, consistently in a positive direction for CPG brands but inconsistently across context. CPG brand recall is penalized less by the addition of a charity partner in non-congruent contexts, while with retail partners, CPG brand recall is penalized less by the addition of second brand in congruent contexts.

$\operatorname{Exp}(B)$ values are significantly higher when the brand owns the context as evident by the higher effect sizes and non-overlapping confidence intervals (charity congruent, $\operatorname{Exp}(B)=0.95(\mathrm{CI}=0.90-0.99)$; charity non-congruent, $\operatorname{Exp}(B)=0.67(\mathrm{CI}=0.56-$ $0.85)$; retailer congruent, $\operatorname{Exp}(B)=0.93(\mathrm{CI}=0.87-0.98)$; retailer non-congruent, $\operatorname{Exp}(B)=0.37(\mathrm{CI}=0.16-0.84))$. Therefore, when any brand $(\mathrm{CPG}$, charity, or retailer) does not own the category context, co-branding's negative effect on brand recall is exacerbated. As there is a greater negative effect on the non-congruent brand than on the congruent brand, $\mathrm{H} 3$ is supported.

\section{Discussion}

This research examined the memorability of online co-branded advertising, when CPG brands partner with charities or retailers, and the effect of ad context on the advertisements' effectiveness. The first contribution is the consistent evidence that adding a second brand to online advertising does not positively affect ad recognition. This is contrary to the expected usage-bias effect, where having more brand users should lead to greater advertising noticeability. One explanation is that both brand users and nonusers do not attend to the second brand sufficiently for it to get processed into memory. Consistent with previous theories of selective attention (e.g., Taylor and Fiske 1978), if the second brand fails to be noticed, then its presence has no opportunity to attract attention to the advertisement. Consequently, the presence of a second brand does not impact an audience's memory of the banner advertisement. Another explanation is that individual user groups associated with co-branded advertisements (e.g., user of both 
Table 2 Main experiment results: brand recall

\begin{tabular}{|c|c|c|c|c|c|c|c|}
\hline & $\begin{array}{l}\text { Owns context } \\
\text { or not }\end{array}$ & Treatment & $\operatorname{Exp}(B)$ & Sig. & Low bound & Up bound & Wald \\
\hline \multirow[t]{10}{*}{ Charity } & \multirow[t]{5}{*}{ Congruent } & Intercept & & 0.11 & & & \\
\hline & & Brand recall & 0.95 & 0.04 & 0.90 & 0.99 & 4.4 \\
\hline & & Brand type: CPG & $\mathrm{NS}$ & 0.20 & & & \\
\hline & & Country: UK & NS & 0.40 & & & \\
\hline & & Country: USA & $\mathrm{N} / \mathrm{A}$ & & & & \\
\hline & \multirow[t]{5}{*}{ Non-congruent } & Intercept & & $<0.01$ & & & \\
\hline & & Brand recall & 0.67 & $<0.01$ & 0.56 & 0.85 & 12.3 \\
\hline & & Brand type: CPG & 50.3 & 0.02 & 1.65 & 1539.1 & 5.0 \\
\hline & & Country: UK & NS & 0.93 & & & \\
\hline & & Country: USA & N/A & & & & \\
\hline \multirow[t]{10}{*}{ Retailer } & \multirow[t]{5}{*}{ Congruent } & Intercept & & 0.03 & & & \\
\hline & & Brand recall & 0.93 & 0.01 & 0.87 & 0.98 & 6.3 \\
\hline & & Brand type: $\mathrm{CPG}$ & 5.34 & 0.04 & 1.05 & 27.2 & 4.1 \\
\hline & & Country: UK & NS & 0.48 & & & \\
\hline & & Country: USA & $\mathrm{NS}$ & 0.54 & & & \\
\hline & \multirow[t]{5}{*}{ Non-congruent } & Intercept & & $<0.01$ & & & \\
\hline & & Brand recall & 0.37 & 0.02 & 0.16 & 0.84 & 5.6 \\
\hline & & Brand type: CPG & NS & 0.78 & & & \\
\hline & & Country: UK & $\mathrm{NS}$ & 0.13 & & & \\
\hline & & Country: USA & NS & 0.67 & & & \\
\hline
\end{tabular}

brands, user of brand A only, user of brand B only, non-user of both), process the advert differently, potentially leading to a canceling-out effect on overall ad recognition.

In the context of online banner advertisements, the presence of another brand has a negative effect on brand recall. Such effect is worsened for brands when the context of the advertisement focuses on the other brand in the partnership. Our finding has parallels to Schmidt and Hitchon's study (1999), where the inclusion of a social issue in a print advertisement distracted sufficiently to result in fewer brand attributes being remembered. While interference effects are typically studied in the context of multiple competitive advertisements shown in a pod (e.g., Danaher et al. 2008), our results suggest that interference effects exist within an advertisement, among non-competitive stimuli. This supports a dual-brand memory interference effect and earlier presumptions that co-branded advertising is more likely to evoke comparisons between the brands than to act as an interpretive frame for the other brand (Levin and Levin 2000).

\section{Implications}

While it is often speculated that advertising two brands is better than advertising one (Helmig et al. 2008; Leuthesser et al. 2003), this study challenges the merit of such 
beliefs. Within the scope of online banner advertisements, our findings establish that promoting two brands (as opposed to one) has no positive effect on the consumer's memory of the ad. Consumers also have a lower propensity of retrieving co-advertised brands from memory. Combined, these two findings indicate that the net effect of advertising on memory-related outcomes is the same or lower than that for single-brand advertising. These results suggest that marketers using online banner advertisements should avoid using a co-branded advertising strategy to increase attention to the advertisement and brand.

The results have implications for the return on investment from advertising expenditure, which will vary substantively depending on if the costs of advertising are shared or borne by one brand in the pair. Economical benefits may exist if the advertising cost is shared between two brands (Son et al. 2006). A simple example is that if coadvertising is half the cost of advertising alone, but results in a $20 \%$ decrease in brand recall, then advertisers still benefit from this arrangement. However, establishing the exact trade-off between cost-efficiencies and what is lost can be difficult and depends on numerous factors such as the size of the brands, type of alliance, consonance between brands, and which is the primary/secondary brand being advertised. Yet, if the objective is to increase memorability for both brands, separate advertising, whereby each brand can have its own advertising space, may be more effective in the long run.

Should marketers choose or feel pressure (e.g., from distributors) to pursue cobranding in advertising, owning the creative context of the advertisements will dampen the negative effects of the second (non-focal) brand on an audiences' memory of the brand. This also implies that a secondary brand has little to gain from co-advertising. As such, advertisers should avoid paying for advertising where the ad context is dominated by their partner's category.

\section{Limitations and future research}

Despite covering many conditions, this research suffers from limitations of scope and would benefit from further replication. Our findings are confined to the context of online advertising, where both brands have a static presence on screen at the same time. In practice, advertisers use a range of different online strategies, such as animation and pop-up, and further testing is needed to see if co-branding may be effective in such domains. Co-branding within different marketing vehicles may elicit different effects. As such, we recommend replicating this study in other advertising media, such as television, where both brands could be present at different times, and so both could potentially have their "day in the sun." The extension to other markets, such as emerging markets, would help to identify the relevant boundary conditions.

While many different co-brand scenarios exist, this study examined only two combinations: $\mathrm{CPG}$ brands with charities and CPG brands with retailers. Extending this study to other co-branding scenarios (e.g., tie-in advertising or TV program promotions) is recommended. We also recommend incorporating contexts where more than two brands are present (e.g., an event sponsored by multiple brands). Further, featuring two brands in different categories, but with an obvious link, such as a drink and snack brand combination is an another area for further investigation to determine if the link in category usage also translates to a stronger link between two brands from 
each category, such that both are easier to retrieve. Finally, the findings on context also warrant further investigation to see if there could be mixed contexts that represent both brands, or if a neutral context negates the observed effects.

\section{References}

Ahluwalia, R. (2002). How prevalent is the negativity effect in consumer environments? Journal of Consumer Research, 29, 270-280.

Anderson, M. C., \& Neely, J. H. (1996). Interference and inhibition in memory retrieval. In E. L. Bjork \& R. A. Bjork (Eds.), Memory control (1st ed., pp. 237-313). Cambridge: Academic Press.

Atkin, C., \& Block, M. (1983). Effectiveness of celebrity endorsers. Journal of Advertising Research, 23, $57-$ 61.

Besharat, A., \& Langan, R. (2014). Towards the formation of consensus in the domain of co-branding: current findings and future priorities. Journal of Brand Management, 21, 112-132.

Bettman, J. R. (1979). Memory factors in consumer choice: a review. Journal of Marketing, 43, 37-53.

Bigné, E., Currás-Pérez, R., \& Aldás-Manzano, J. (2012). Dual nature of cause-brand fit: influence on corporate social responsibility consumer perception. European Journal of Marketing, 46, 575-594.

Bjork, E. L., \& Bjork, R. A. (1996). Memory. San Diego, CA: Academic Press.

Blankenship, A. B., \& Whitely, P. L. (1941). Proactive inhibition in the recall of advertising material. Journal of Social Psychology, 13, 311-322.

Bloom, P. N., Hoeffler, S., Keller, K. L., \& Meza, C. E. B. (2006). How social-cause marketing affects consumer perceptions. MIT Sloan Management Review, 47, 49-55.

Burke, R. R., \& Srull, T. K. (1988). Competitive interference and consumer memory for advertising. Journal of Consumer Research, 15, 55-68.

Dahlén, M., \& Lange, F. (2005). Advertising weak and strong brands: who gains? Psychology \& Marketing, $22,473-488$.

Danaher, P. J., Bonfrer, A., \& Dhar, S. (2008). The effect of competitive advertising interference on sales of packaged goods. Journal of Marketing Research, 45, 211-225.

Dréze, X., \& Hussherr, F.-X. (2003). Internet advertising: is anybody watching? Journal of Interactive Marketing, 17, 8-23.

du Plessis, E. (1994a). Recognition versus recall. Journal of Advertising Research, 34, 75-91.

du Plessis, E. (1994b). Understanding and using likeability. Journal of Advertising Research, 34, 95-95.

Erdogan, B. Z., \& Drollinger, T. (2008). Endorsement practice: how agencies select spokespeople. Journal of Advertising Research, 48, 573-582.

Erfgen, C., Zenker, S., \& Sattler, H. (2015). The vampire effect: when do celebrity endorsers harm brand recall? International Journal of Research in Marketing, 32(2), 155-163.

Gammoh, B. S., Voss, K. E., \& Chakraborty, G. (2006). Consumer evaluation of brand alliance signals. Psychology \& Marketing, 23, 465-486.

Grossman, R. P. (1997). Co-branding in advertising: developing effective associations. Journal of Product \& Brand Management, 6, 191-301.

Harrison, F. (2013). Digging deeper down into the empirical generalization of brand recall. Journal of Advertising Research, 53, 181-185.

Helmig, B., Huber, J.-A., \& Leeflang, P. S. H. (2008). Co-branding: the state of the art. Standard Business Reporting, 60, 359-377.

Kapferer, J.-N. (1995). Strategic brand management—new approaches to creating and evaluating brand equity. London: Kogan Page Limited.

Kent, R., \& Allen, C. (1994). Competitive interference effects in consumer memory for advertising: the role of brand familiarity. Journal of Marketing, 58, 97-105.

Lee Thomas, M., Mullen, L. G., \& Fraedrich, J. (2011). Increased word-of-mouth via strategic cause-related marketing. International Journal of Nonprofit and Voluntary Sector Marketing, 16, 36-49.

Leuthesser, L., Kohli, C., \& Suri, R. (2003). $2+2=5$ ? A framework for using co-branding to leverage a brand. The Journal of Brand Management, 11, 35-47.

Levin, I. P., \& Levin, A. M. (2000). Modeling the role of brand alliances in the assimilation of product evaluations. Journal of Consumer Psychology, 9, 43-52.

Pechmann, C., \& Stewart, D. W. (1990). The effects of comparative advertising on attention, memory, and purchase intentions. Journal of Consumer Research, 17, 180-191. 
Peled, J. (2010). Online advertising planning WARC. http://www.warc.com/Content/ContentViewer. aspx?MasterContentRef=e5789df9-a522-4739-918f-f2e77a5f7b79\&q=Online+Advertising+Planning.

Rao, A. R., Qu, L., \& Ruekert, R. W. (1999). Signaling unobservable product quality through a brand ally. Journal of Marketing Research, 36, 258-268.

Romaniuk, J. (2009). The efficacy of brand-execution tactics in TV advertising, brand placements and Internet advertising. Journal of Advertising Research, 49, 143-150.

Romaniuk, J. (2013). Sharing the spotlight: is there room for two brands in one advertisement? Journal of Advertising Research, 53, 247-250.

Rossiter, J. R., \& Bellman, S. (2005). Marketing communications: theory and applications. Frenchs Forest: Pearson Education.

Schmidt, T. L., \& Hitchon, J. C. (1999). When advertising and public relations converge: an application of schema theory to the persuasive impact of alignment ads. Journalism \& Mass Communication Quarterly, $76,433-455$.

Singh, S. N., Rothschild, M. L., \& Churchill Jr., G. A. (1988). Recognition versus recall as measures of television commercial forgetting. Journal of Marketing Research, 25, 72-80.

Son, M., Hahn, M., \& Kang, H. (2006). Why firms do co-promotions in mature markets? Journal of Business Research, 59, 1035-1042.

Taylor, S. E., \& Fiske, S. T. (1978). Salience, attention, and attribution: top of the head phenomena. Advances in Experimental Social Psychology, 11, 249-288.

Vaughan, K., Beal, V., \& Romaniuk, J. (2016). Can brand user really remember advertising more than nonusers? Testing an empirical generalization across six advertising awareness measures. Journal of Advertising Research, 56, 311-320.

Venkatesh, R., Mahajan, V., \& Muller, E. (2000). Dynamic co-marketing alliances: when and why do they succeed or fail? International Journal of Research in Marketing, 17, 3-31.

Voss, K. E., \& Gammoh, B. S. (2004). Building brands through brand alliances: does a second ally help? Marketing Letters, 15, 147-159.

Wang, A., \& Muehling, D. D. (2010). The effects of audio-visual and visual-only cues on consumers' responses to co-branded advertising. Journal of Marketing Communications, 16, 307-324.

Washburn, J. H., Till, B. D., \& Priluck, R. (2000). Co-branding: brand equity and trial effects. Journal of Consumer Marketing, 17, 591-604.

Wyer, R. S., \& Srull, T. K. (1981). The processing of social stimulus information: a conceptual integration. In R. Hastie, T. M. Ostrom, E. B. Ebbesen, R. S. Wyer, D. L. Hamilton, \& D. E. Carlston (Eds.), Person memory: the cognitive basis of social perception (pp. 227-294). New York, US: Psychology Press.

Yi, Y. (1990). Cognitive and affective priming effects of the context for print advertisements. Journal of Advertising, 19, 40-48. 